\title{
Dengue and dengue hemorrhagic fever in the State of Pernambuco, 1995-2006
}

\author{
Dengue e febre hemorrágica do dengue \\ no Estado de Pernambuco, 1995-2006
}

\author{
Marli Tenório Cordeiro ${ }^{1,2}$, Hermann Gonçalves Schatzmayr ${ }^{3}$, \\ Rita Maria Ribeiro Nogueira ${ }^{3}$, Valdete Felix de Oliveira ${ }^{1}$, \\ Wellinton Tavares de Melo ${ }^{4}$ and Eduardo Freese de Carvalho ${ }^{5}$
}

\begin{abstract}
In Pernambuco, the first dengue cases occurred in 1987. After a seven-year interval without autochthonous cases, a new epidemic occurred in 1995. Important aspects of the dengue epidemics during the period 1995-2006 have been analyzed here, using epidemiological, clinical and laboratory data. A total of 378,374 cases were notified, with 612 confirmed cases of dengue hemorrhagic fever and 33 deaths. The mortality rate was 5.4\%. The incidence rate increased from 134 to 1,438/100,000 inhabitants, corresponding to the epidemics due to serotypes 2 and 3 , in 1995 and 2002, respectively. Dengue mainly affected adults (20-49 years); 40.7\% were male and 59.3\% were female. From 2003 onwards, the number of cases among individuals younger than 15 years old increased. Out of 225 dengue hemorrhagic fever cases, $42.7 \%$ primary and $57.3 \%$ secondary infections were identified $(p=0.0279)$. Neurological manifestations were also observed. From 2002 onwards, serotypes 1 , 2 and 3 were circulating; serotype 3 was predominant.
\end{abstract}

Key-words: Dengue. Dengue virus. Dengue hemorrhagic fever. Epidemiology.

\section{RESUMO}

Em Pernambuco, os primeiros casos de dengue ocorreram em 1987. Após intervalo de 7 anos sem casos autóctones, em 1995 ocorreu uma nova epidemia. Foram analisados aspectos relevantes das epidemias (1995-2006), utilizando-se dados epidemiológicos, clínicos e laboratoriais. Um total de 378.374 casos foi notificado, com 612 casos confirmados de febre hemorrágica do dengue e 33 óbitos. A taxa de mortalidade foi de 5.4\%. A taxa de incidência aumentou de 134 para 1.438/100.000 habitantes, correspondente às epidemias pelos sorotipos 2 e 3, em 1995 e 2002, respectivamente. O dengue acometeu principalmente pessoas adultas (20-49 anos); 40,7\% do sexo masculino e 59,3\%, feminino. A partir de 2003, aumentou o número de casos em menores de 15 anos. Entre 225 casos de dengue hemorrágico, foram identificadas $42,7 \%$ e $57,3 \%$ infecções primárias e secundárias, respectivamente $(p=0.0279)$. Manifestações neurológicas também foram observadas. A partir de 2002, circularam os sorotipos 1, 2 e 3; predominando o sorotipo 3.

Palavras-chaves: Dengue. Virus dengue. Febre hemorrágica do dengue. Epidemiologia.

Over the last two decades, dengue fever (DF) and dengue hemorrhagic fever/dengue shock syndrome (DHF/DSS) have emerged as important arthropod-borne viral diseases associated with high morbidity among human populations in the Americas ${ }^{32}$. On these continents, the dengue virus (DENV) has shown hyperendemic characteristics, as the consequence of co-circulation of multiple serotypes ${ }^{69}$. The reemergence of dengue in Latin America occurred during the 1960s (Caribbean and Venezuela) and in Colombia in the 1970s9.
In Brazil, the first laboratory-confirmed dengue outbreak occurred in 1982 in the northern region (Boa Vista, State of Roraima), with isolation of serotypes 1 (DENV-1) and 4 (DENV$4)^{31}$. Following this, there were no further cases reported until 1986, when an epidemic of DENV-1 occurred in the State of Rio de Janeiro ${ }^{36}$, followed by the introduction of DENV-2 and DENV-3 in 1990 and 2000, respectively, resulting in several epidemics in this country ${ }^{23} 2427$. After the introduction of DENV-3, explosive epidemics were observed almost all over the country ${ }^{37}$. From 1986

\footnotetext{
1. Laboratório Central de Saúde de Pública, Secretaria de Saúde do Estado de Pernambuco, Recife, PE. 2. Laboratório de Virologia e Terapia Experimental, Centro de Pesquisas Aggeu Magalhães, Fundação Oswaldo Cruz, Recife, PE. 3. Laboratório de Flavivirus, Departamento de Virologia, Instituto Oswaldo Cruz, Fundação Oswaldo Cruz, Rio de Janeiro, RJ. 4. Gerência Geral de Vigilância em Saúde, Secretaria de Saúde do Estado de Pernambuco, Recife, PE. 5. Departamento de Saúde Coletiva, Centro de Pesquisas Aggeu Magalhães, Fundação Oswaldo Cruz, Recife, PE.

Address to: Dra. Marli Tenório Cordeiro. Laboratório de Virologia e Terapia Experimental/CPqAM//FIOCRUZ. Av. Moraes Rego, s/n, Campus da UFPE, Cidade Universitária, 50670-420 Recife, PE, Brasil.

Tel: 5581 2101-2624; Fax: 5581 2101-2651.

e-mail: marli@cpqam.fiocruz.br

Recebido para publicação em: 02/08/2007

Aceito em: 05/11/2007
} 
to 2006 , more than four million dengue cases were reported in the country ${ }^{19}$.

In the State of Pernambuco, the first dengue outbreak occurred in 1987, with 2,118 cases reported. However, this outbreak was brought under control within the same year by the vector control measures undertaken. In 1995, after experiencing a seven-year interval without confirmed autochthonous dengue cases, a new epidemic occurred with the introduction of DENV2. Since the introduction of DENV-3 in 2002, the three serotypes are now circulating in Pernambuco ${ }^{3}$. From 1995 to 2006, approximately 380,000 dengue fever cases were reported in this state. In the present study, we describe important epidemiological characteristics of the dengue/dengue hemorrhagic fever cases that were reported during the epidemics in the State of Pernambuco during the period from 1995 to 2006.

\section{MATERIAL AND METHODS}

Study site. The current study was conducted in the State of Pernambuco, in the northeastern region of Brazil, which covers an area of $98,938 \mathrm{~km}^{2}$ and had an estimated population of $8,457,267$ inhabitants in 2006. The state has 185 municipalities, but the majority of the population lives in the Metropolitan Region, which includes Recife (the state capital) and 18 other municipalities ${ }^{18}$.

Study population. The 378,374 cases included in this study had acute febrile illness suggestive of dengue infection. Information on patients was recorded on standardized forms completed by health staff and reported to health surveillance authorities in the state. The cases were analyzed following clinical, epidemiological and laboratorial criteria that were in accordance with guidelines from the Brazilian Ministry of Health ${ }^{20}$. The Research Ethics Committee of the Aggeu Magalhães Research Center, Fundação Oswaldo Cruz, Brazil, approved this study in accordance with CNS Resolution 196/1996.

Dengue case definition. Dengue fever (classical dengue) and dengue hemorrhagic fever were defined in accordance with WHO guidelines ${ }^{39}$.

Data sources and analysis. Data from reported dengue cases was available in the official information system of the Pernambuco State Health Department (SSPE). Entomological data was obtained from the SSPE vector control program. Laboratory diagnosis data was available from the Central Public Health Laboratory (LACEN-PE). Dengue incidence rates were calculated according to age group and gender for all municipalities, for each year, by using census population data ${ }^{18}$ as the denominators. The mean incidence rates for the state, according to age group and gender, was calculated by using the median points of estimated populations for the years 1995 to $2006^{18}$. The statistical analysis was performed with the aid of the Stat Pac Inc. software for Windows (version 10.2; Bloomington, MN, USA), which is available at http://www.statpac.com and Microsoft Office Excel version 3.0 (Microsoft, USA). Odds ratios (OR) and 95\% confidence intervals (CI) were calculated. The chi-squared test was used for comparisons of means and proportions and $\mathrm{p}<0.05$ was considered statistically significant.
Sample collection. Specimens from 91,480 suspected cases were sent to LACEN-PE for dengue infection confirmation and/or virus isolation, together with individual standardized forms containing basic demographic data, symptom onset dates, sample collection data and clinical manifestations. Aliquots of serum samples were stored at $-70^{\circ} \mathrm{C}$ and $-20^{\circ} \mathrm{C}$ for virus isolation and serological tests, respectively.

Dengue diagnosis. The laboratory diagnosis of dengue was undertaken using virological and serological methods, depending on the dates of disease onset and specimen collection. A total of 120,000 serum samples received by the laboratory were subjected to dengue IgM-capture ELISA analysis using an in-house method (MAC-ELISA) ${ }^{12}$ and/or a commercial kit (PanBio Pty Ltd, Brisbane, Australia) and testing was performed in accordance with the manufacturer's instructions. A total of 9,000 acute serum samples were processed for virus isolation using $\mathrm{C} 6 / 36$ cells ${ }^{11}$; virus isolates were identified by the indirect fluorescent antibody assay ${ }^{7}$. The reverse transcription-polymerase chain reaction (RT-PCR) for detecting and typing $\mathrm{DENV}^{13}$ was carried out on 840 acute-phase serum samples and specimens from fatal cases. The hemagglutination inhibition assay $(\mathrm{HI})^{2}$ was used on paired serum samples from $225 \mathrm{DHF}$ cases, to classify the type of immune response, in accordance with World Health Organization (WHO) criteria ${ }^{39}$.

\section{RESULTS}

From 1995 to $2006,378,374$ dengue cases were reported in Pernambuco and 612 DHF cases were confirmed, with 33 deaths (Table 1). In 1995, the main vector, Aedes aegypti, was detected in 42 municipalities; in 1996 and 1999, it was confirmed in 125 and 173 municipalities, respectively; and in 2002 it reached all

Table 1 - Number of dengue/dengue hemorrhagic fever cases reported in the State of Pernambuco: incidence rates per 100,000 inbabitants, numbers of deaths, case fatality rates and dengue virus serotype predominance, according to year of occurrence, 1995-2006.

\begin{tabular}{|c|c|c|c|c|c|c|c|c|c|}
\hline \multirow[b]{2}{*}{ Years } & \multicolumn{2}{|c|}{ Reported cases } & \multirow{2}{*}{$\frac{\text { Ratio }}{\text { DHF/DF }}$} & \multicolumn{3}{|c|}{ DHF cases } & \multicolumn{3}{|c|}{ DENV serotypes (\%) } \\
\hline & $\mathrm{NC}$ & IR & & $\mathrm{NC}$ & $\mathrm{D}$ & MR (\%) & 1 & 2 & 3 \\
\hline 1995 & 9,982 & 134.1 & - & 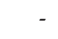 & - & & 13.0 & 87.0 & - \\
\hline 1996 & 22,722 & 307.1 & $1: 3,787$ & 6 & 1 & 16.7 & 34.0 & 66.0 & - \\
\hline 997 & 32,627 & 437.0 & $1: 2,510$ & 13 & - & - & 94.0 & 6.0 & - \\
\hline 1998 & 52,633 & 699.6 & $1: 1,120$ & 47 & 1 & 2.1 & 62.0 & 38.0 & - \\
\hline 1999 & 35,099 & 463.0 & $1: 1,253$ & 28 & 1 & 3.6 & 78.0 & 22.0 & - \\
\hline 2000 & 27,949 & 353.0 & $1: 735$ & 38 & - & - & 72.0 & 28.0 & - \\
\hline 2001 & 17,112 & 213.7 & $1: 349$ & 49 & 1 & 2.0 & 76.0 & 24.0 & - \\
\hline 2002 & 116,245 & $1,437.8$ & $1: 342$ & 340 & 20 & 5.9 & 18.0 & 9.0 & 73.0 \\
\hline 2003 & 26,083 & 329.6 & $1: 1,242$ & 21 & 3 & 14.3 & 1.0 & 1.0 & 98.0 \\
\hline 2004 & 6,337 & 76.9 & $1: 396$ & 10 & - & - & 0.0 & 0.0 & 100.0 \\
\hline 2005 & 12,990 & 154.4 & $1: 618$ & 21 & 2 & 9.5 & 5.0 & 0.0 & 95.0 \\
\hline 2006 & 18,595 & 218.7 & $1: 563$ & 33 & 4 & 12.1 & 0.0 & 6.0 & 94.0 \\
\hline otal & 378,374 & $4,721.6$ & 1:618 & 612 & 33 & 5.4 & & & \\
\hline
\end{tabular}

DHF: dengue hemorrhagic fever, DENV: dengue virus, NC: number of cases, IR: incidence rate, DHF/DF: dengue hemorrhagic fever/dengue fever, D: death, MR: mortality rate.

Source: Surveillance and Epidemiological Service of the Central Public Health Laboratory, Pernambuco State Health Department, Brazil. 
185 municipalities, with an infestation index $>1 \%$. In 1995, 9,982 cases were reported, corresponding to an incidence rate (IR) of 134.1 cases per 100,000 inhabitants. In 1996, the number of cases was $128 \%$ higher (IR = 307.1/100,000 inhabitants) and in 1998, an incidence of 699.6/100,000 inhabitants was reached (Table 1). Over the next three years (1999-2001), a reduction of $32 \%$ in the number of cases was observed. The major epidemic caused by DENV-3 that occurred in 2002 affected all 185 municipalities, and the number of cases was 7.8 times greater than in $2001 ; 116,245$ cases were reported (IR $=1,437.8 / 100,000$ inhabitants). In 2003, the number of cases was 4.5 times lower than in 2002 (IR = 329.6/100,000 inhabitants). Thereafter, 2004-2006 was an endemic period. In all outbreaks, the majority of cases occurred in the first half of the year (Figure 1), usually peaking in the months of April and May. In the outbreaks of 1995 to 1997 and in the 2002 epidemic, the bulk of case occurrences were in the Metropolitan Region of Recife (MRR), with $42.5 \%$ of the total number of cases in these four years; other regions were responsible for the majority of cases in 1998-2001 and 2003-2006.

Over this 12-year period, the incidence rate in the city of Recife ranged from 28 to 2,378/100,000 inhabitants. The 86,247 cases reported in Recife represented $22.8 \%$ of the total number of cases occurring in Pernambuco. Other municipalities in the metropolitan region, such as Jaboatão dos Guararapes, Olinda, Cabo de Santo Agostinho and Camaragibe, presented mean incidence rates of 259, 384, 722 and 1019 cases/100,000 inhabitants, respectively. The total number of cases reported from 1995 to 2006 in the five major regions of the State of Pernambuco were: 1) Metropolitan Region of Recife, 176,458 cases; 2) Agreste, 101,027 cases; 3) Mata, 55,245 cases; 4) Sertão, 31,812 cases; and 5) São Francisco, 14,101 cases. Table 2 shows the annual incidence rates in these geographic regions. From 1995 to 2001 , there was co-circulation of DENV-1 and DENV-2. In 2002, after the introduction of DENV-3, circulation of all three serotypes was detected; nevertheless, there was predominance of DENV-3. The

Table 2 - Incidence rate of dengue cases reported in the State of Pernambuco (per 100,000 inbabitants), according to geographic regions, 1995-2006.

\begin{tabular}{lrrrrr}
\hline \multirow{5}{*}{ Year } & \multicolumn{5}{c}{ Incidence rate } \\
\cline { 2 - 6 } & Sertão & \multicolumn{1}{c}{ São } & Agreste & Mata & MRR \\
\hline 1995 & 14.0 & 11.8 & 48.3 & 72.2 & 262.2 \\
1996 & 19.4 & 62.9 & 186.1 & 228.2 & 523.9 \\
1997 & 37.9 & 24.5 & 252.7 & 723.9 & 609.1 \\
1998 & 196.6 & 142.4 & $1,099.0$ & 678.9 & 682.1 \\
1999 & 310.0 & 399.0 & 748.7 & 415.5 & 360.3 \\
2000 & 526.0 & 452.5 & 447.5 & 356.0 & 234.5 \\
2001 & 393.8 & 440.7 & 218.5 & 147.4 & 154.0 \\
2002 & 638.4 & 375.0 & $1,122.6$ & $1,402.0$ & $2,001.8$ \\
2003 & 781.6 & 422.4 & 587.0 & 106.0 & 87.2 \\
2004 & 56.1 & 72.3 & 121.9 & 90.7 & 54.8 \\
2005 & 321.2 & 193.0 & 131.2 & 110.6 & 128.5 \\
2006 & 203.1 & 256.1 & 199.0 & 228.2 & 224.3 \\
IRP & $3,561.1$ & $2,960.5$ & $5,297.8$ & $4,503.8$ & $5,232.6$ \\
\hline
\end{tabular}

MRR: Metropolitan Region of Recife, IRP: incidence rate for whole study period Source: Pernambuco State Health Department, Brazil. percentages of DENV isolation, by year, are shown in Table 1. The predominant DENV serotypes in each epidemic/endemic year are shown in Figure 1.

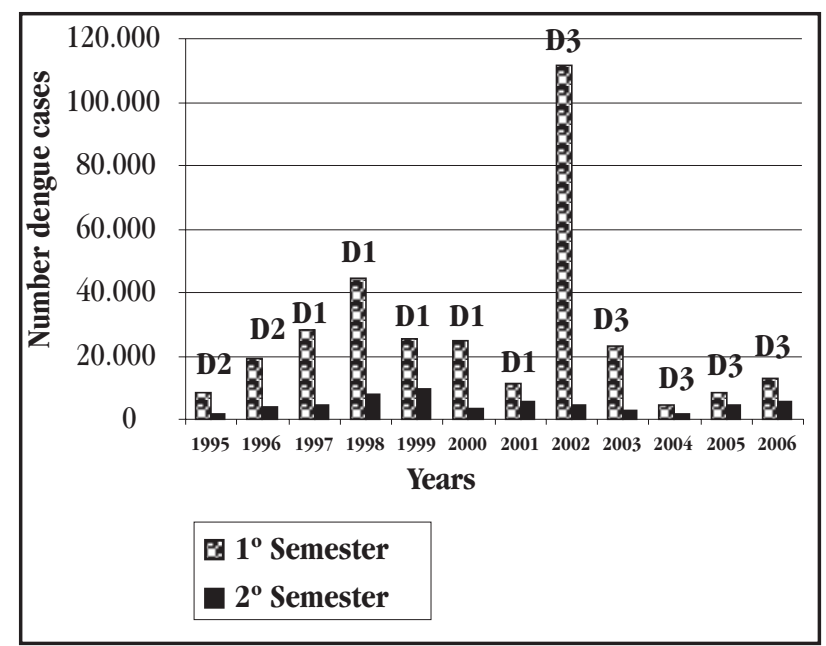

D1: DENV-1, D2: DENV-2, D3: DENV-3.

Source: Surveillance and Epidemiological Service of the Central Public Health Laboratory, Pernambuco State Health Department, Brazil.

Figure 1 - Annual distribution of dengue fever cases reported in the State of Pernambuco, over the period 1995-2006, according to semester of occurrence and the dengue virus serotypes predominant in each year.

The overall age distribution showed that $55 \%$ of the dengue cases occurred in adults in the age range from 20 to 49 years old (Table 3). During the period 1995-2006, dengue incidence was consistently higher in adults, reaching up to 1,938/100,000 inhabitants in the 20-49 years age group, in 2002. When dengue cases were classified into three age groups, i.e. $<5$ years, 5 to 14 years and $\geq 15$ years old (Figure 2 ), it was observed that the $\geq 15$ years age group was the most affected. From 2003 onwards, the group less than 15 years old was more affected than in previous dengue outbreaks. In 2003, the incidence of cases among children younger than 5 years old was higher than in the 5 to 14 years age group. The dengue incidence rates in $<1$ year, 1-4 years and 5-14

Table 3 - Distribution of dengue fever and dengue bemorrbagic fever cases reported in the State of Pernambuco, in terms of numbers and percentages (\%) of cases and incidence rate (per 100,000 inbabitants), according to age group, 1995-2006.

\begin{tabular}{|c|c|c|c|c|c|c|}
\hline \multirow{2}{*}{$\begin{array}{l}\text { Age } \\
\text { (years) }\end{array}$} & \multicolumn{3}{|c|}{ Reported dengue cases } & \multicolumn{3}{|c|}{ DHF cases } \\
\hline & $\mathrm{NC}$ & $\%$ & IR & $\mathrm{NC}$ & $\%$ & IR \\
\hline$<1$ & 4,299 & 1.1 & $2,665.3$ & 5 & 0.8 & 3.1 \\
\hline $1-4$ & 15,420 & 4.1 & $2,375.2$ & 19 & 3.1 & 2.9 \\
\hline $5-9$ & 22,047 & 5.8 & $2,663.4$ & 37 & 6.1 & 4.5 \\
\hline $10-14$ & 30,898 & 8.2 & $3,475.8$ & 51 & 8.3 & 5.7 \\
\hline $15-19$ & 39,169 & 10.4 & $4,425.2$ & 62 & 10.1 & 7.0 \\
\hline $20-49$ & 207,945 & 55.0 & $6,245.9$ & 316 & 51.6 & 9.5 \\
\hline $50-79$ & 55,660 & 14.7 & $4,748.8$ & 117 & 19.1 & 10.0 \\
\hline$\geq 80$ & 2,196 & 0.6 & $2,198.1$ & 5 & 0.8 & 5.0 \\
\hline NI & 740 & 0.2 & & - & - & \\
\hline Total & 378,374 & & $4,721.6$ & 612 & & 7.6 \\
\hline
\end{tabular}

NI: not informed, DHF: dengue hemorrhagic fever, NC: number of cases, IR: incidence rate.

Source: Pernambuco State Health Department, Brazil. 


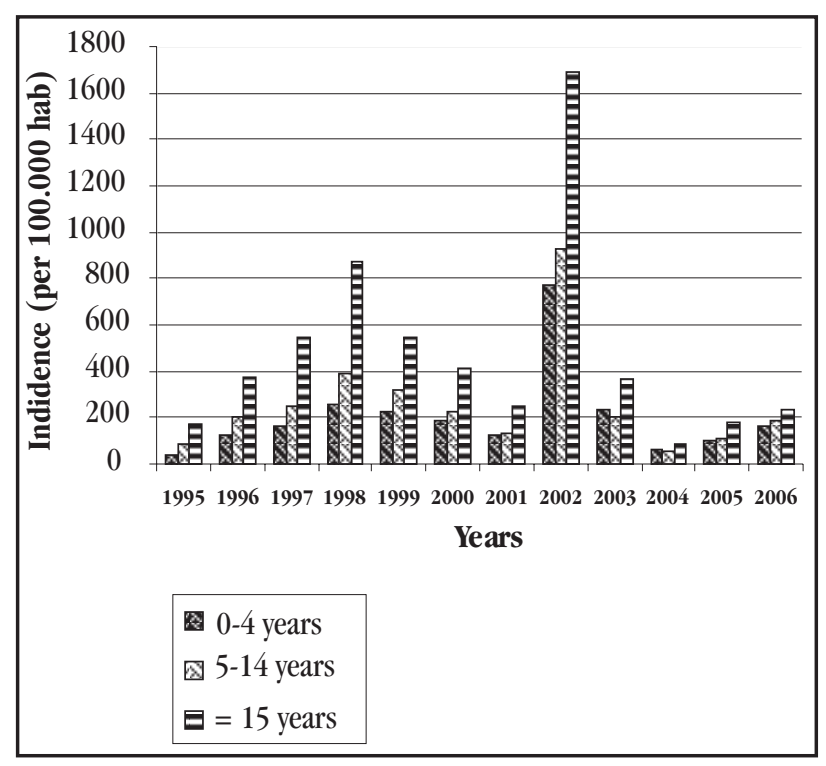

Source: Surveillance and Epidemiological Service of the Central Public Health Laboratory, Pernambuco State Health Department, Brazil.

Figure 2 - Distribution of dengue cases reported in the State of Pernambuco, over the years 1995 to 2006, according to incidence rates for three different age groups (0-4 years; 5-14 years; $\geq 15$ years).

years age groups were 326, 210 and 199/100,000 inhabitants, respectively. Table 4 shows the annual distribution of the numbers and incidence rates of cases, by age groups.

Regarding gender, over this 12-year period, the male to female ratio was constant at 1:1.5. From 1995 to 2006, 153,120 cases $(40.7 \%$ ) were reported in male patients and 224,425 cases (59.3\%) in female patients. A statistically significant difference in the frequencies of cases between female and male patients was found. Female individuals were more affected $[\mathrm{OR}=2.15$; $95 \%$ confidence interval $(\mathrm{CI})=2.129-2.168 ; \chi^{2}=26,878.65$ $(\mathrm{p}<0.0001)]$. The gender and age distributions were very similar when the data for each year were stratified.

The first DHF cases were confirmed in 1996, after the introduction of DENV-2 into the State. From 1996 to 2006, 612 cases of DHF were confirmed, with 33 deaths. The case-fatality rate ranged from $2.0 \%$ to $16.7 \%$, with a mean of $5.4 \%$ (Table 1 ). In the epidemic year of 1998 , the ratio of DHF to DF cases was $1: 1,120$ and mortality was $2.1 \%$ (1/47); while in the epidemic year of 2002 (DENV-3), the ratio of DHF to DF cases was 1:342 and mortality was $5.9 \%$ (Table 1 ). The age distribution among DHF cases over this period is presented in Table 3. It was observed, among the DHF cases, that $81.7 \%(n=500)$ occurred in individuals $\geq 15$ years old, and mainly in adults between 20 and 49 years old (median age 47 years; modal age 23 years). However, the incidence rate in the 50 to 79 years age group was somewhat similar to that in the 20 to 49 years age group (Table $3)$. Only $18.3 \%$ of the patients $(n=112)$ were younger than 15 years old. Regarding gender, there were 236 (38.6\%) male cases and 376 (61.4\%) female cases, thus representing one male case to 1.6 female cases. There was no statistically significant difference between the genders $\left[\mathrm{OR}=1.23\right.$ (CI $0.98-1.53$ ); $\chi^{2}=3.29$ $(\mathrm{p}=0.070)]$. Regarding the type of immune serological response, the results from hemagglutination inhibition assays performed on paired serum samples from 225 DHF cases characterized 96 (42.7\%) DHF cases as primary infection and 129 (57.3\%) DHF cases as secondary (sequential) dengue infection, in accordance with the WHO criteria ${ }^{39}$. There was a statistically significant difference $(p=0.0279)$ in secondary infection as a risk factor for DHF. Among 13 fatal cases analyzed, one case of primary and five of secondary dengue infection were characterized.

The laboratory studies performed at LACEN-PE on 116,098 specimens (24,518 second samples) from 91,480 suspected dengue cases confirmed 48,300 cases $(52.8 \%)$ by at least one of the following tests: virus isolation, RNA viral detection, positive anti-dengue IgM ELISA or fourfold rise in HI titer. Analyses conducted on the data from these positive cases showed that the main signs and symptoms presented were consistent with dengue fever (Table 5). The most common hemorrhagic manifestations in 468 laboratory-positive DHF cases were petechiae, metrorrhagia, bleeding gums, epistaxes, melena and hematemesis (Table 5). Neurological manifestations were reported in 32 patients with

Table 4 - Distribution of dengue cases and incidence rates (per 100,000 inbabitants), according to age group, in the State of Pernambuco, 1995-2006.

\begin{tabular}{|c|c|c|c|c|c|c|c|c|c|}
\hline \multirow[b]{3}{*}{ Years } & \multicolumn{8}{|c|}{ Age groups (years) } & \multirow{3}{*}{$\begin{array}{c}\geq 65-79 \\
\text { NC/IR }\end{array}$} \\
\hline & $<1$ & $1-4$ & $5-9$ & $10-14$ & $15-19$ & $20-34$ & $35-49$ & $50-64$ & \\
\hline & $\mathrm{NC} / \mathrm{IR}$ & $\mathrm{NC} / \mathrm{IR}$ & $\mathrm{NC} / \mathrm{IR}$ & $\mathrm{NC} / \mathrm{IR}$ & $\mathrm{NC} / \mathrm{IR}$ & $\mathrm{NC} / \mathrm{IR}$ & $\mathrm{NC} / \mathrm{IR}$ & $\mathrm{NC} / \mathrm{IR}$ & \\
\hline 1995 & $0 / 0$ & $329 / 45.9$ & $589 / 63.3$ & $978 / 105.5$ & $935 / 111.1$ & $3,735 / 212.3$ & $1,993 / 187.5$ & $998 / 155.9$ & $435 / 130.0$ \\
\hline 1996 & $157 / 104.3$ & $789 / 130.2$ & $1,272 / 155.7$ & $2,131 / 243.9$ & $1,999 / 240.4$ & $8,134 / 446.2$ & $4,817 / 415.0$ & $2,443 / 360.2$ & $959 / 172.2$ \\
\hline 1997 & $257 / 169.2$ & $969 / 158.5$ & $1,719 / 208.6$ & $2,553 / 289.7 /$ & $3,295 / 392.6$ & $11,273 / 612.3$ & $7,163 / 611.2$ & $3,738 / 546.5$ & $1,503 / 274.0$ \\
\hline 1998 & $368 / 240.4$ & $1,631 / 264.8$ & $2,736 / 329.6$ & $3,892 / 438.4$ & $5,516 / 652.3$ & $18,431 / 992.9$ & $11,182 / 946.4$ & $5,893 / 855.4$ & $2,692 / 527.1$ \\
\hline 1999 & $316 / 205.0$ & $1,442 / 232.4$ & $2,251 / 269.2$ & $3,254 / 363.9$ & $3,954 / 464.1$ & $11,336 / 605.7$ & $7,125 / 598.2$ & $3,781 / 545.0$ & $1,517 / 298.1$ \\
\hline 2000 & $335 / 211.1$ & $1,174 / 183.7$ & $1,537 / 191.8$ & $2,264 / 261.9$ & $3,074 / 349.2$ & $9,140 / 458.9$ & $6,093 / 462.3$ & $3,018 / 387.4$ & $1,314 / 249.8$ \\
\hline 2001 & $252 / 157.0$ & $764 / 118.2$ & $951 / 117.4$ & $1,340 / 153.3$ & $1,726 / 193.9$ & $5,361 / 266.0$ & $3,959 / 296.9$ & $1,813 / 230.2$ & $920 / 164.3$ \\
\hline 2002 & $1,277 / 787.9$ & $5,012 / 768.4$ & $6,591 / 806.0$ & $9,204 / 1,043.5$ & $11,867 / 1,320.8$ & $38,580 / 1,895.4$ & $26,327 / 1,955.2$ & $11,723 / 1,474.8$ & $5,564 / 971.7$ \\
\hline 2003 & $533 / 325.7$ & $1,382 / 209.9$ & $1,482 / 179.5$ & $1,940 / 217.9$ & $2,821 / 311.0$ & $8,230 / 400.3$ & $5,477 / 402.8$ & $2,762 / 344.3$ & $1,443 / 260.1$ \\
\hline 2004 & $174 / 105.3$ & $333 / 50.1$ & $431 / 51.7$ & $544 / 60.6$ & $797 / 87.1$ & $1,953 / 94.1$ & $1,233 / 89.8$ & $578 / 71.4$ & $294 / 49.7$ \\
\hline 2005 & $249 / 147.6$ & $582 / 85.8$ & $936 / 110.0$ & $1,034 / 112.8$ & $1,295 / 138.6$ & $4,092 / 192.8$ & $2,914 / 207.7$ & $1,296 / 156.9$ & $592 / 104.0$ \\
\hline 2006 & $381 / 223.5$ & $1,013 / 147.7$ & $1,552 / 180.6$ & $1,764 / 190.4$ & $1,890 / 200.1$ & $5,406 / 252.0$ & $4,003 / 282.2$ & $1,833 / 219.7$ & $748 / 121.3$ \\
\hline
\end{tabular}

NC: number of cases, IR: incidence rate.

Source: Pernambuco State Health Department, Brazil. 
Table 5 - Frequency (\%) of signs and symptoms observed in laboratorypositive dengue fever/dengue hemorrbagic fever cases that occurred in the State of Pernambuco, Brazil, 1995-2006.

\begin{tabular}{|c|c|c|}
\hline \multirow[b]{2}{*}{ Signs and symptoms } & \multicolumn{2}{|c|}{ Frequency (\%) } \\
\hline & $\begin{array}{c}\text { DF } \\
\left(\mathrm{n}^{\circ}=48,300\right)\end{array}$ & $\begin{array}{c}\text { DHF } \\
\left(\mathrm{n}^{-}=468\right)\end{array}$ \\
\hline Fever & 91.4 & 100.0 \\
\hline Headache & 84.1 & 97.3 \\
\hline Myalgia & 61.0 & 96.0 \\
\hline Retroorbital pain & 60.9 & 90.2 \\
\hline Arthralgia & 56.4 & 79.5 \\
\hline Prostration & 52.8 & 100.0 \\
\hline Rash & 49.2 & 52.6 \\
\hline Nausea & 43.0 & 96.0 \\
\hline Abdominal pain & 30.9 & 74.0 \\
\hline Pruritus & 27.6 & 62.8 \\
\hline Vomiting & 22.8 & 40.5 \\
\hline Anorexia & 20.1 & 100.0 \\
\hline Chills & 17.0 & 95.8 \\
\hline Petechiae & 9.0 & 18.0 \\
\hline Diarrhea & 6.3 & 48.5 \\
\hline Epistaxis & 1.4 & 5.6 \\
\hline Metrorrhagia & 0.1 & 16.3 \\
\hline Bleeding gums & 0.1 & 9.2 \\
\hline Melena & 0.0 & 4.8 \\
\hline Hematemesis & 0.0 & 2.2 \\
\hline Other hemorrhages & 2.1 & 0.0 \\
\hline
\end{tabular}

DF: dengue fever, DHF: dengue hemorrhagic fever, $\mathrm{n}$ : $:$ number of cases.

Source: Central Public Health Laboratory, Pernambuco State Health Department, Brazil.

dengue fever; the most severe cases were: encephalitis (6 cases), meningoencephalitis ( 4 cases) and Guillain-Barré syndrome (3 cases). Anti-dengue IgM was detected in both serum and cerebrospinal fluid samples from these patients.

\section{DISCUSSION}

Over the last 20 years, the incidence of dengue infections in Brazil increased from a reported annual rate of 37 cases per 100,000 inhabitants in 1994 to $454 / 100,000$ inhabitants in $2002^{37}$. In Pernambuco, 378,374 cases have been reported over the last 12 years, and the infection incidence rate increased from 134 cases/100,000 in 1995 to 1,437.8/100,000 inhabitants in 2002, as consequence of DENV and disease dispersion in the State. Despite the efforts to keep the vector density at low levels, this objective was not achieved. According to official data ${ }^{19}$, the vector density (house index) was greater than $1 \%$ in $80-90 \%$ of the municipalities in the country, including in Pernambuco. In Fortaleza, Brazil, it has been observed that dengue outbreaks never occurred when the house index was $<1 \%{ }^{33}$.

As demonstrated in Figure 1, the majority of cases in each outbreak were observed in the first half of the year, similar to what has been observed in other Brazilian states ${ }^{37}$. Nevertheless, it should be pointed out that dengue outbreaks may occur during both halves of the year, as seen in the State of Rio de Janeiro, during epidemics of DENV-1 (January to August 1990) and DENV-2
(October 1990 to May 1991) ${ }^{25}$. The major dengue epidemics in Pernambuco occurred in 1998 and 2002, although dengue activity was observed throughout the 12-year period (Table 1), with cocirculation of DENV-1 and DENV-2 until 2001 and inclusion of serotype 3 from 2002 onwards. The percentages of each serotype isolated from 1995 to 2006, which are shown in Table 1, indicate which DENV serotype predominated in each outbreak (Figure 1). Based on these results, it is highly suggestive that the 1997-1998 epidemics were caused by DENV-1, while DENV-2 was responsible for the 1995-1996 outbreaks and then DENV-3 caused the 2002 epidemic $^{3}$. The replacement of one serotype by another, which is usually observed during epidemics, may be explained by the growing numbers of people who became immune to the former serotype ${ }^{9}$. Nevertheless, it has been shown that DENV-3 (genotype III, Sri Lanka/India) has been able to dislodge the other serotypes when introduced into a new region, thus showing its high infection capacity among the human population ${ }^{4} 926$.

Despite the large number of cases reported in Pernambuco during this period, the number of dengue infections that occurred was probably an underestimate, because the majority of the cases reported are those that were attended at public health services. On the other hand, it could be possible that there was overestimation of the number of cases, particularly during epidemics, considering the percentages of laboratory-confirmed cases (58.2\%), among those subjected to specific tests. Taking into account the five major geographic regions of Pernambuco, the majority of the cases occurred in the Metropolitan Region (46.6\%), which represents only $2.8 \%$ of the total area of the State and is the most densely populated ( $41.8 \%$ of inhabitants). Dengue outbreaks have started from this region and spread to the others. The metropolitan regions of large cities are usually responsible for the majority of cases occurring during epidemics ${ }^{43} 37$. However, when the case incidence rates were examined according to geographic regions (Table 2), it was observed that the Metropolitan Region of Recife and the Agreste region presented nearly the same incidence rate, i.e. 5,232.6 and 5,297.8/100,000 inhabitants, respectively. The Agreste region reported $26.7 \%$ of the total number of cases $(101,027 / 378,374)$.

During the study period, dengue infection affected all age groups, as seen in Table 4. However, the incidence rate was higher among adults, particularly in the 20 to 49 years age group (Table 3). The epidemiology of dengue in Pernambuco presents a feature common to other Brazilian states, in that it is characterized by dengue fever and DHF affecting mainly adults ${ }^{37} 40$. It is feasible that there may have been an underestimation of dengue cases among children in Pernambuco, because dengue infection in children is frequently milder and may be confused with other febrile and exanthematic diseases ${ }^{9} 28$. Thus, it is possible that the diagnosis was not made and/or children did not present significant symptoms during dengue infection and therefore did not seek medical assistance. Nevertheless, it is quite unlikely that DHF cases in children were misdiagnosed, although this issue deserves to be better investigated. The low apparent rate of dengue infection among individuals younger than 15 years of age found in the State of Pernambuco (Figure 2) has also been reported in 
other studies in Brazil ${ }^{303738}$. The different age distribution pattern that was observed in Pernambuco between 2003 and 2006, such that the age group under 15 years old was more affected than in the previous years, and the recent occurrences of DHF in children $<5$ years of age, could represent a change in the epidemiological scenario of the disease in the state. Importantly, in 2003 it was observed that the incidence of cases in children less than 5 years of age was higher than in the 5 to 14 years age group (Figure 2). Recently, an increased rate of DHF cases among children in the Amazon region of Brazil and in other Brazilian states has been reported $^{2937}$.

Regarding gender, the higher proportion of dengue cases among female patients $(59.3 \% ; \mathrm{p}<0.0001)$ was also observed in the epidemic that occurred in Belém (Pará) ${ }^{35}$. Nevertheless, among DHF cases there was no statistically significant difference relating to gender $(\mathrm{p}=0.070)$, despite the higher number of cases among females than among males. In Cuba, the gender distribution in three DHF epidemics was different; the male-to-female ratio of DHF cases in 1981 was 1:5.4, while in 1997 it was 1:1 and in 2001-2002 it was 2.04:1, as described by González et al5. The high mortality rate for DHF (5.4\%), observed in Pernambuco over the period 1996 to 2006, is in accordance with other studies in Brazil $^{3740}$ and may have been due to difficulties in classifying DHF cases according to the WHO guidelines ${ }^{39}$. From 1996 to 2006, 612 DHF cases were confirmed: 604 cases were classified as DHF (grades I and II) and only eight cases as dengue shock syndrome (grades III and IV). The total number of DHF cases confirmed in Pernambuco may have been underestimated $(0.16 \%)$, despite the ratio of 1:618, of DHF to DF cases. In the 2002 epidemic (DENV-3), among 116,245 dengue cases reported, only 340 DHF cases were confirmed, i.e. a ratio of 1:342. In the State of Rio de Janeiro, in 2002 (DENV-3) epidemic, among 288,245 dengue cases reported, 1,831 DHF cases and 91 deaths ${ }^{23}$ were confirmed. The ratio of DHF to DF cases was 1:157, i.e. almost half of the rate found in Pernambuco. Interestingly, in the 2002 epidemic, 696 cases were reported as DHF in Pernambuco, although only 340 cases fulfilled the WHO criteria. The main difficulty in classifying DHF cases was the lack of laboratory data. Importantly, hemoconcentration (one of the WHO criteria for DHF) has become a less frequently confirmed event during the course of the disease, so that several suspected DHF cases were classified as classical dengue with complications, following the Brazilian surveillance and epidemiological guidelines ${ }^{1920}$. Improvement of the standard WHO guidelines for DHF classification is needed, as suggested by Marzochi ${ }^{15}$ and Rigau-Pérez et $\mathrm{al}^{34}$. Regarding the type of serological immune response, according to our data, it seems that sequential dengue infection (57.3\%) was an important risk factor for the development of DHF $(\mathrm{p}=0.0279)$. However, the occurrence of DHF in $42.7 \%$ of the cases of primary infection should be seen as a warning sign for medical personnel. The increasing number of DHF cases that have occurred in the state over the last few years is probably associated with sequential infections. However, since a considerable number of DHF cases have been detected in primary infections, other factors such as host genetics ${ }^{10}$ and viral strain virulence ${ }^{9}$ must be taken into account. This issue ought to be better investigated. The occurrence of DHF cases and deaths among patients experiencing primary infection that was observed in Pernambuco has also been reported in epidemics that occurred in other Brazilian states ${ }^{421} 2240$.

The main signs and symptoms presented by laboratoryconfirmed cases, as shown in Table 5, are common features in dengue. However, dengue fever cases with neurological manifestations, which were first studied in Brazil by Chimelli et $\mathrm{al}^{1}$ and were observed in Pernambuco during the period of the present study, should be seen as an important warning sign for medical personnel during epidemics. Neurological disorders associated with dengue infection have been referred to as dengue encephalopathy due to immunopathological responses and not to central nervous system infection ${ }^{8}$. Nevertheless, several studies have shown evidence that the dengue virus has neurovirulence properties and can cause encephalitis in both primary and secondary dengue infections ${ }^{14172126}$. As proposed by Marzochi ${ }^{16}$, it is essential to establish a sensitive and specific dengue surveillance system in this country, particularly when the incidence decreases. Considering that no dengue vaccine is yet available, it is absolutely necessary to improve the vector control program; the reference services for DHF cases, in order to have better patient management; and the surveillance services for acute febrile illness, in order to provide early diagnostic confirmation.

\section{ACKNOWLEDGEMENTS}

We thank Dr. Cynthia Braga for her critical review of the manuscript.

\section{REFERENCES}

1. Chimelli L, Hahn MD, Barreto Neto M, Ramos RG, Dias M, Gray F. Dengue: Neuropathological findings in 5 fatal cases from Brazil. Clinical Neuropathology 9:157-162, 1990.

2. Clarke DH, Casals J. Techniques for hemagglutination and hemagglutinationinhibition with arthropod-borne viruses. American Journal of Tropical Medicine and Hygiene 7: 561-573, 1958.

3. Cordeiro MT. Epidemiologic, clinical and virological observations on dengue in the state of Pernambuco, Brazil. In: XIII Encontro Nacional de Virologia, 2002, Águas de Lindóia. São Paulo. Anais da Virus Reviews \& Research 7: 54-54, 2002.

4. De Simone TS, Nogueira RMR, Araújo ESM, Guimarães FR, Santos FB, Schatzmayr HG, Souza RV, Teixeira Filho G, Miagostovich MP. Dengue virus surveillance: the co-circulation of DENV-1, DENV-2 and DENV-3 in the State of Rio de Janeiro, Brazil. Transactions of the Royal Society of Tropical Medicine and Hygiene 98: 553-562, 2004.

5. González D, Castro OE, Kouri G, Perez J, Martinez E, Vazquez S, Rosário D, Cancio R, Guzmán MG. Classical dengue hemorrhagic fever resulting from two dengue infections spaced 20 years or more apart: Havana, Dengue 3 epidemic, 2001-2002. International Journal of Infectious Diseases 9: 280-285, 2005.

6. Gubler DJ. Epidemic dengue/dengue hemorrhagic fever as a public health, social and economic problem in the 21st century. Trends in Microbiology 10: 100-103, 2002 .

7. Gubler DJ, Kuno G, Sather GE, Velez M, Oliver A. Mosquito cell cultures and specific monoclonal antibodies in surveillance for dengue viruses. The American Journal of Tropical Medicine and Hygiene 33: 158-165, 1984.

8. Gubler DJ, Kuno G, Waterman SH. Neurologic disorders associated with Dengue infection. In: Annals of the International Conference on Dengue/Dengue haemorrhagic fever. Kuala Lumpur, Malaysia, p.290-306, 1983. 
9. Guzmán MG, Kouri G. Dengue and dengue hemorrhagic fever in the Americas: lessons and challenges. Journal of Clinical Virology 27: 1-3, 2003.

10. Halstead SB. Dengue in the Americas and Southeast Asia: Do they differ? Pan American Journal of Public Health 20: 407- 415, 2006.

11. Igarashi A. Isolation of a Singh's Aedes albopictus cell clone sensitive to dengue and chikungunya viruses. Journal of General Virology 40: 531-544, 1978.

12. Kuno G, Gómez I, Gubler DJ. Detecting artificial anti-dengue IgM immunecomplexes using an enzyme-linked immunosorbent assay. American Journal of Tropical Medicine and Hygiene 36: 153-159, 1987.

13. Lanciotti RS, Calisher CH, Gubler DJ, Chang G J, Vorndam AV. Rapid Detection and Typing of Dengue viruses from clinical samples by using Reverse Transcriptase Polymerase chain Reaction. Journal of Clinical Microbiology 30: 545-551, 1992.

14. Leão RNQ, Oikawa T, Rosa EST, Yamaki JT, Rodrigues SG, Vasconcelos HB, Sousa MRS, Tsukimata JK, Azevedo RSS, Vasconcelos PFC. Isolation of dengue 2 virus from a patient with central nervous system involvement (transverse myelitis). Revista da Sociedade Brasileira de Medicina Tropical 35: 401-404, 2002.

15. Marzochi KBF. Dengue - Classificação clínica. Cadernos de Saúde Pública 7: 409-415, 1991.

16. Marzochi KBF. Dengue endêmico: o desafio das estratégias de vigilância. Revista da Sociedade Brasileira de Medicina Tropical 37: 413-415, 2004.

17. Miagostovich MP, Ramos RG, Nicol AF, Nogueira RMR, Schatzmayr HG. Retrospective study on dengue fatal cases. Clinical Neuropathology 16: 204-208, 1997.

18. Ministério da Saúde. DATASUS. Instituto Brasileiro de Geografia e Estatística (IBGE): Censos demográficos e contagem populacional; para os anos intercensitários, estimativas preliminares dos totais populacionais, estratificadas por idade e sexo pelo Ministério da Saúde da Saúde/SE/Datasus, Brasil, [Cited $2007 \mathrm{Fev} 5$ ]. Available from http://tabnet.datasus.gov.br/cgi/deftohtm.exe?ibge/ cnv/poppe.def, Cited 2007.

19. Ministério da Saúde. Secretaria de Vigilância em Saúde. [Cited 2007 Mar 15]. Available from http://portal.saude.gov.br/portal/svs/, Cited 2007.

20. Ministério da Saúde. Secretaria de Vigilância em Saúde. Dengue: diagnóstico e manejo clínico. $2^{\text {a }}$ edição, Editora do Ministério da Saúde, Brasília, DF, 2005. Available from < http://portal.saude.gov.br/portal/arquivos/pdf/dengue_manejo_ clinico_2006.pdf, 2005.

21. Nogueira RMR, Filippis AMB, Coelho JM0, Sequeira PC, Schatzmayr HG, Paiva FG, Ramos AMO, Miagostovich MP. Dengue virus infection of the Central nervous system (CNS) a case report from Brazil. Southeast Asian Journal of Tropical Public Health 33: 68-71, 2002.

22. Nogueira RMR, Miagostovich MP, Cunha RV, Zagne SMO, Gomes FP, Nicol AF, Coelho JCO, Schatzmayr HG. Fatal primary dengue infections in Brazil. Transactions of the Royal Society of Tropical Medicine and Hygiene 93: 418, 1999.

23. Nogueira RMR, Miagostovich MP, Filippis AMB, Pereira MAS, Schatzmayr HG. Dengue virus type 3 in Rio de Janeiro, Brazil. Memórias do Instituto Oswaldo Cruz 96: 925-926, 2001

24. Nogueira RMR, Miagostovich MP, Lampe E, Schatzmayr HG. Isolation of Dengue virus type 2 in Rio de Janeiro. Memórias do Instituto Oswaldo Cruz 85: 253, 1990
25. Nogueira RMR, Miagostovich MP, Lampe E, Souza RW, Zagne SMO, Schatzmayr HG. Dengue epidemic in the state of Rio de Janeiro, Brazil, 1990-1: co-circulation of dengue 1 and dengue 2 serotypes. Epidemiology and Infection 111: 163-170, 1993.

26. Nogueira RMR, Schatzmayr HG, Filippis AMB, Santos FB, Cunha RV, Coelho JO, Souza LJ, Guimarães FR, Araújo, ESM, De Simone, TS, Baran M, Teixeira Jr G, Miagostovich MP. Dengue virus type 3, Brazil, 2002. Emerging Infectious Diseases 11: 1376-1381, 2005.

27. Nogueira RMR, Schatzmayr HG, Miagostovich MP, Farias MFDB, Farias Filho JC. Virological study of a Dengue type 1 epidemic at Rio de Janeiro. Memórias do Instituto Oswaldo Cruz 83: 219-225, 1988.

28. Nogueira SA. Dengue. Jornal de Pediatria 75: 9-14, 1999.

29. Nogueira SA. The challenge of diagnosing dengue in children. Jornal de Pediatria 81: 191, 2005.

30. Nunes-Araújo FR, Ferreira MS, Nishioka SD. Dengue fever in Brazilian adults and children: assessment of clinical findings and their validity for diagnosis, Annals of Tropical Medicine and Parasitology 97: 415-419, 2003.

31. Osanai CH, Rosa APAT, Tang AT, Amaral RS, Passos ADC, Tauil PL. Surto de Dengue em Boa Vista, Roraima. Revista do Instituto de Medicina Tropical de São Paulo 25: 53-54, 1983.

32. Pinheiro FP, Corber SJ. Global situation of dengue and dengue haemorrhagic fever, and its emergence in the Americas. World Health Statistics Quarterly 50: 161-169, 1997.

33. Pontes RJS, Freeman J, Oliveira-Lima JW, Hodgson C, Spielman A. Vector densities that potentiate dengue outbreaks in a Brazilian city. The American Journal of Tropical Medicine and Hygiene 62: 378-383, 2000.

34. Rigau-Pérez JG, Bonilla GL. The Puerto Rico Association of Epidemiologists. An evaluation of modified case definitions for the detection of dengue hemorrhagic fever. Puerto Rico Health Sciences Journal 18: 347-352, 1999.

35. Rosa APAT, Vasconcelos PFF, Travassos da Rosa ES, Rodrigues SG, Mondet B, Cruz ACR, Sousa MR, Travassos da Rosa JFS. Dengue Epidemic in Belém, Pará, Brazil, 1996-1997. Emerging Infectious Diseases 6: 298-301, 2000.

36. Schatzmayr HG, Nogueira RMR, Rosa APAT. An Outbreak of Dengue virus at Rio de Janeiro-1986. Memórias do Instituto Oswaldo Cruz 81: 245-246, 1986.

37. Siqueira JB, Martelli CMT, Coelho GE, Simplício ACR, Hatch DL. Dengue and dengue hemorrhagic fever, Brazil, 1981-2002. Emerging Infection Disease 11: 48-53, 2005.

38. Teixeira MG, Barreto ML, Costa MC, Ferreira LD, Vasconcelos PF, Cairncross S Dynamics of dengue virus circulation: a silent epidemic in a complex urban area, Tropical Medicine International Health 7: 757-762, 2002.

39. World Health Organization, 1997. Dengue haemorrhagic fever: Diagnosis, treatment, prevention and control. 2nd edition. World Health Organization, Geneva, 1997.

40. Zagne SMO, Alves VGF, Nogueira RMR, Miagostovich MP, Lampe E, Tavares W. Dengue haemorrhagic fever in the state of Rio de Janeiro, Brazil: a study of 56 confirmed cases. Transactions of the Royal Society of Tropical Medicine and Hygiene 88: 677-679, 1994. 